\title{
Essentially Contested Concepts and Semantic Externalism
}

\author{
Simon J. Evnine \\ Department of Philosophy University of Miami, USA \\ sevnine@miami.edu
}

\begin{abstract}
In 1956, W.B. Gallie introduced his idea of essentially contested concepts. In my paper, I offer a novel interpretation of his theory and argue that his theory, thus interpreted, is correct. The key to my interpretation lies in a condition Gallie places on essentially contested concepts that other interpreters downplay or dismiss: that the use of an essentially contested concept must be derived "from an original exemplar whose authority is acknowledged by all the contestant users of the concept." This reveals a similarity between Gallie's views and the semantic externalist views of Hilary Putnam, and others, about natural kind terms like "water" and "tiger." I argue that natural kind terms and terms for essentially contested concepts are two species of a single semantic genus. In the case of natural kind terms, a term refers to a natural kind, the exemplars are instances of that kind, and the relation between the exemplars and anything to which the term applies is co-membership of the kind. In the case of terms for essentially contested concepts, a term refers to an historical tradition, the exemplar is a stage or temporal part of that tradition, and the relation between the exemplar and anything to which the term refers is being the heir of. This allows me to understand the contests that alerted Gallie to the phenomenon of essentially contested concepts as contests over the ownership of historical traditions.
\end{abstract}

\section{Keywords}

Gallie - Putnam - essentially contested concepts - semantic externalism - traditions 
In 1956, W.B. Gallie introduced his theory of essentially contested concepts. ${ }^{1}$ In this paper I aim to accomplish two things. The first is to suggest what I believe to be a new way of understanding Gallie's theory. The second is to recommend this theory by extending and developing it. In a nutshell, I take Gallie's theory to be this. There is a class of terms, including "Christianity" and "art" which feature prominently in Gallie's paper, the reference of which is tied to some exemplary phenomenon, and which correctly refer to something just in case that thing has a certain relation, being the heir of, to that exemplary phenomenon. The exemplary phenomena and the things to which such terms correctly refer through their relation to these exemplary phenomena, constitute historical traditions, which I take to be (though this is not necessary for the development of the theory) concrete, temporally extended particulars. The contests around which Gallie organizes his paper arise because people fight for ownership, as it were, of traditions that are important to them. Such contests are endemic to traditions though not, strictly speaking, essential to them. (Thus, Gallie's theory would have better been called, not a theory of essentially contested concepts, but a theory of terms for endemically contested entities. For the sake of continuity with the existing literature, I shall continue to speak of essentially contested concepts, or terms.) Readers familiar with the semantic externalist theories of Hilary Putnam and Saul Kripke will recognize that my account of essentially contested terms is very similar to their account of natural kind terms. ${ }^{2}$ In fact, I shall argue that natural kind terms and essentially contested terms are two species of the same semantic genus.

As I mentioned, my interpretation of Gallie is novel. His work has been discussed almost wholly within the context of social and political philosophy. In the process, it has been viewed from the perspective of other ideas which, it is suggested, it resembles. Thus, relativism and incommensurability, family resemblances, the Rawlsian distinction between concept and conception, reflective equilibrium, open concepts, and normativity have all been brought

1 W.B. Gallie "Essentially Contested Concepts", Proceedings of the Aristotelian Society, 56 (1956), 167-98. This was reprinted, with minor changes, in W.B. Gallie, Philosophy and the Historical Understanding (London: Chatto and Windus, 1964). Page references in the text are to the reprinted version.

2 See, for example, Hilary Putnam, "The Meaning of 'Meaning', Mind, Language and Reality: Philosophical Papers, vol. 2 (Cambridge: Cambridge University Press, 1975) and Saul Kripke, Naming and Necessity (Cambridge: Harvard University Press, 1980). If I am right in my interpretation, Gallie deserves some historical credit since he presented his theory more than a decade before the development of similar ideas by Putnam and Kripke. 
in to illuminate Gallie's idea. ${ }^{3}$ Correlatively with these theoretical perspectives has been an emphasis on a certain range of examples. It is sometimes uncritically assumed that most of our social, political, and ethical concepts are cases of the phenomenon Gallie is concerned with, if anything is at all. My own approach to Gallie will involve re-assessing the range of examples of the phenomenon he is interested in.

Let us begin by approaching Gallie's target informally. Gallie is interested in concepts that are associated with a certain kind of contest or conflict in their use, function, or application. It is initially the character of these contests that sets apart the target concepts (or terms) and makes them of interest. These are contests that cannot be settled by rational means but in which rational considerations are not idle. People can be induced to switch sides in these contests by the production of evidence or argument, even though such things will not be rationally compelling to everyone. This fact, for Gallie, seems to mean that the conflicts involved are not simply conflicts of value or preference. But the contests of interest are to be distinguished from another type of contest, as well. For they do not embody the kind of confusion that could be resolved by simply stipulating a definition and, if necessary, introducing new terms or concepts. Contestants, in other words, are not simply talking past each other. Straightforward conflicts over value and confused conflicts in which a resort to stipulation is useful are, of course, both frequently encountered. But Gallie's interest is caught by the idea that there are contests that are neither; in these contests, as he puts it deliberately toying with paradox, we are dealing with

3 Relativism and incommensurability: Steven Lukes, "Relativism: Cognitive and Moral", Proceedings of the Aristotelian Society, supplementary volume 48 (1974), 165-89; family resemblances: Ernest Gellner, Selected Philosophical Themes, Volume II: Contemporary Thought and Politics (London: Routledge, 1974) and Peter Ingram, "Open Concepts and Contested Concepts", Philosophia, 15 (1985), 41-59; concept and conception: Steven Lukes, Power: A Radical View, second edition (London: MacMillan, 2005) and Christine Swanton, “On the 'Essential Contestedness' of Political Concepts”, Ethics, 95 (1985), 811-27; reflective equilibrium: Swanton, “On the 'Essential Contestedness' of Political Concepts”; open concepts: Alasdair MacIntyre, “The Essential Contestability of Some Social Concepts", Ethics, 84 (1973), 1-9; normativity: Lukes, "Relativism: Cognitive and Moral", Power: A Radical View, and John Gray "On the Contestability of Social and Political Concepts", Political Theory, 5 (1977), $331-48$. 
"concepts the proper use of which inevitably involves endless disputes about their proper uses on the part of their users" (158).

We are probably all familiar with examples of such conflicts. One person says something like: "Conservatism is really about not rushing into social change." Another replies: "No, it's about preserving the rights of the individual against government encroachment." Philosophers hearing such disputes are, perhaps, often prone to want to resolve them into one or other of the kinds of dispute from which Gallie distinguishes his target phenomenon. On the one hand, we might think that the two speakers are simply interested in, and value, different things; worrying about what Conservatism is is just a red herring, the invocation of the concept nothing but a Shibboleth with which each participant seeks to sanction her own preferences. Alternatively, we may want to say that "Conservatism" is ambiguous; it has, indeed, been used to name both of these things; let "Conservatism*" name the first and "Conservatism+" name the second. Now there's nothing to argue about. But if Conservatism is an example of an essentially contested concept, both these responses incorrectly identify the nature of the contest portrayed in my minimal dialogue.

What, then, is Gallie's theory of essentially contested concepts? Unfortunately, it is hard to say precisely, owing to some confusions in his presentation, but it clearly has something to do with seven conditions that he lays out: 4

(I) The concept must be appraisive in the sense that it signifies or accredits some kind of valued achievement.

(II) This achievement must be of an internally complex character, for all that its worth is attributed to it as a whole.

(III) Any explanation of its worth must therefore include reference to the respective contributions of its various parts or features... In fine, the accredited achievement is initially variously describable.

(IV) The accredited achievement must be of a kind that admits of considerable modification in the light of changing circumstances ... I shall call the concept of any such achievement 'open' in character...

(V) ... [E] ach party [must] recognize[] the fact that its own use of [the concept] is contested by those of other parties... [It must be used] both aggressively and defensively.

4 The wording of the first five conditions is taken from 161, that of the last two from 168. All language not in square brackets is direct quotation; the rest is minimal paraphrase. 
(VI) [The concept, or the use of the concept, must be derived] from an original exemplar whose authority is acknowledged by all the contestant users of the concept.

(VII) [It must be probable, or plausible, that $]$ the continuous competition for acknowledgment as between the contestant users of the concept enables the original exemplar's achievement to be sustained or developed in optimum fashion.

Gallie begins by presenting the first five conditions together, says that each is necessary, and that (together) they "explain sufficiently what it means for a concept to count as essentially contested" (168). One naturally thinks, therefore, that the conjunction of the first five conditions is meant to be a necessary and sufficient condition for something's being an essentially contested concept. However, Gallie immediately goes on to say, apparently contradicting his "sufficiently explain," that conditions I-V "do not include any clear suggestion ... for distinguishing an essentially contested concept from a concept which can be shown... to be radically confused" (168). This latter task, he thinks, is somehow connected with conditions VI and VII. One might then suppose that the conjunction of all seven conditions constitutes the claim about the nature of essentially contested concepts, but again, the waters are muddied by Gallie's claim that conditions VI and VII are not conditions on what it is for something to be an essentially contested concept but conditions for the use of an essentially contested concept's being, in some sense, justified. There is, therefore, no consistent position explicitly articulated over exactly what an essentially contested concept is. Some interpretation is required.

My interpretation of Gallie takes condition VI as central to the phenomenon in which he is interested. ${ }^{5}$ Although Gallie is himself confused about its status, an unbiased reading of his paper will surely confirm that it is of central importance to what he takes himself to be doing; hence, by neglecting this condition, one seriously risks missing his point altogether. Let us look at how condition VI works in an adaptation of one of the 'live' cases discussed at length by Gallie.

5 It is precisely over this condition and its significance that my interpretation differs from all those described in the second paragraph of this paper, for they all either downplay it or reject or ignore it altogether. Gellner makes opposition to it central to his understanding of Gallie; I shall discuss Gellner's views on this extensively in section 3. Gray and Lukes make no reference to it. Ingram breezily dismisses it (on the basis of a single unhappy alleged counterexample which I will mention later) and takes it as a condition satisfied only by concepts that are not really in the target class. Swanton does see the importance of the condition but does not, I think, treat it adequately. 
Consider the expression "Christianity." ${ }^{6}$ This provides an excellent example of a term that initially exhibits the kind of contestedness that defies rational resolution but to which such discussion is not irrelevant. To focus only on the United States today, and to present matters in a highly simplified and schematic (but I hope still intelligible) way, different groups of users of the term take it to apply to radically different values, actions, or people. Some see capitalism, self-reliance, personal responsibility, and punishment as representing the true essence of Christianity and hence those things properly describable as "Christian." Others find that essence in charity, love, peace activism, forgiveness, and tolerance. Partisans of each view may be inclined to think that what the other party calls "Christianity" is not real Christianity. No doubt this opposition is overly simple, but no-one living in the us could fail to detect some contest over the term "Christianity" between what we might call the Christian Right and the Christian Left. ${ }^{7}$ Now, why think that this contest is not of one of the kinds from which Gallie's target phenomenon is distinguished? Perhaps the parties to the contest are simply opposing their different values to each other and the question of which set of values is the essence of Christianity is just an irrelevance? Certainly, people with one set of the values in question will oppose them to those in the other set. Or why not think that the contest can be settled by showing that each of the parties is just using the term "Christianity" with a different sense and that once this is recognized, there is no real point of contention between them? ${ }^{8}$ The reason is clear. There is an historical

6 I think there is some latitude in whether we take the analysis as focusing on the abstract noun "Christianity," the general noun "Christian," or the adjective "Christian," on the assumption that these terms are closely interdefinable. Mutatis mutandis for all other cases.

7 My claims are so schematic and over-simplified that to attempt to support them with a one or two quotations for each side would be so easily accomplished as to be almost worthless. An internet search of "Christian Right versus Christian Left" brings up a number of relevant sources, of which I reference just Clare Snyder-Hall, "Christian Right Calls Christian Left 'A Rising Power," Tikkun Daily (website), http://www.tikkun.org/tikkundaily/2011/03/14/ christian-right-calls-christian-left-a-rising-power/ (accessed Nov 18, 2013)(and the embedded lecture therein by Dr. Mark Smith).

8 Not surprisingly, those who ignore or downplay condition VI think that Gallie is wrong for supposing that these kinds of cases can be separated. Thus Gellner: "I suspect that no such general differential is available" (Selected Philosophical Themes, Volume II: Contemporary Thought and Politics, 97). And Gray (referring the point to Gellner): "it is not at all evident how we are to distinguish concepts which have an essentially contested character from concepts which are simply radically confused, or general words whose uses conceal a diversity of distinguishable concepts from general words which really denote an essentially contested concept" ("On the Contestability of Social and Political Concepts", 337). 
phenomenon, what Gallie calls an exemplar, and each of the contesting parties claims for itself a certain relation to that historical phenomenon, a relation such that if it obtains in one case, it cannot obtain in the other. The natures of both the exemplar and the contested relation to it will be examined much more closely in the following section. But roughly and provisionally, we can identify the exemplar in this case as something that includes the Bible and the person and biography of Jesus Christ, and the relation as being the heir of. ${ }^{9}$ The reason that the contesting parties cannot simply choose new names and go on their own separate ways is that they are fighting over who gets to keep the family silver. There is a real, not illusory, contest between the two parties as to which represents the true continuation of an historical movement or tradition that includes, along with much else, the Bible and Jesus.

Before turning to a more thorough examination of the exemplar and the contested relation to it, I want to make a few remarks about the other conditions Gallie lays down on essentially contested concepts. The first requires that an essentially contested concept be appraisive and that its use signify or accredit a valued achievement. The use of an essentially contested term may be appraisive in two related senses: it may accredit the achievement implicit in something's having the right relation to the exemplar (to something's being the true heir of the Bible and Jesus), and it may (perhaps usually will) accord a value (positive or negative) to the exemplar that is transferred to whatever the term can be applied to now through the relation that obtains between it and the exemplar. So, the Christian Right and the Christian Left, both positively valuing the exemplar - something that includes both the Bible and Jesus Christ may contest between themselves as to which of them really is its heir; while a Nieztschean third party, contemning the exemplar, may positively value, or disvalue less, whichever of these parties she judges has failed to achieve heirship to the exemplar.

Condition II states that the "achievement must be of an internally complex character, for all that its worth is attributed to it as a whole." Here I think Gallie refers to the exemplar in his use of the word "achievement." Any concrete reality is internally complex and this is especially so for the kinds of things Gallie is concerned with. Clearly the Bible and the person and life of Jesus Christ are internally complex - there are many books in the Bible, many different values seem to be recommended in it, many puzzling events involving Jesus, etc. This

9 With respect to my characterization of the exemplar here, I repeat that this is rough, provisional, and not exhaustive. There is certainly a lot more that should be included in anything more than the schematic version I am giving here. See the following section for some discussion of the types of things that might be included. 
internal complexity is crucial to the existence of the kind of contest Gallie is interested in. For example (with the understanding again that my treatment of the case is overly simple and schematic), the Christian Right and the Christian Left may relate themselves to the exemplar on account of the values and portrayal of God emphasized, respectively, in the Old Testament and the New Testament. The exemplar, being internally complex, contains both these elements but the contesting parties prioritize them differently.

Condition $\mathrm{V}$ is where the notion of contest is brought in to the picture, so in some sense, it clearly plays a very important role. On my interpretation, although this condition will often be true of terms or concepts in the target class, it need not be. Nothing in the relation of heirship implies the existence of rival claimants; and even if there are rival claimants, it is not obvious that each must know of the others' existence. Nonetheless, where an exemplar is rich in internal complexity, especially where it contains elements that are in tension with each other, under ordinary circumstances it is highly likely that groups will evolve that prioritize the elements of this internal complexity differently and hence that a contest will emerge over which party is the real heir of the exemplar. (I prefer, therefore, to think of such contests as endemic to the phenomena under discussion rather than as essential to them.) And of course, it is the fact that this has happened in many salient cases, over art, Christianity, and others, that has brought the target concepts to our attention and forced on us a consideration of how they work. So for Gallie, condition V has something of the role of a reference fixer for the term "essentially contested concept"; it may not be a necessary truth that an essentially contested concept satisfies condition $\mathrm{V}$, but given the way the concept of an essentially contested concept has been introduced, it is perhaps close to being a priori that an essentially contested concept satisfies condition V. Given that it was not until the 1970 s that Kripke firmly established the distinction between necessity and a priority, and given that necessity and essence are often taken to be closely allied, Gallie might therefore be forgiven for thinking that the concepts he was interested in were indeed essentially contested rather than merely of a kind almost inevitably to be contested.

Condition VII, recall, is that the very contestedness of the concept be seen by the contestants as contributing to the sustainment or optimal development of the phenomenon in question. Gallie may have been inspired by the liberal idea, propounded so forcefully in Mill's On Liberty, that honest disagreement about things is good for everyone involved. ${ }^{10}$ (And this would explain why some commentators on Gallie take essentially contested concepts to be a

10 Thanks to a referee for bringing this to my attention. 
distinctive feature of liberal societies, a position I reject below.) But Gallie's Condition VII goes further than Mill and it seems to me that it can hold only in very exceptional circumstances. The problem is that recognition that a contest is necessary for the optimal development of some phenomenon would almost inevitably inject an element of pretense into the conflict itself. Contestants over the mantle of Christianity have happily burnt and tortured one another. But even less extreme manifestation of the conflict is hard to reconcile with the view that the contest is just the vigorous and healthy exercising of the exemplar's destiny. Condition VII may have some plausibility in certain cases though. Gallie introduces the condition through his invented example of conflict over championship in a kind of sport, and he also discusses extensively the concept of art, itself not implausibly taken as involving a playful component. It may be that Gallie was led to generalize too broadly from the ludic character of these examples.

\section{Essentially Contested Concepts and Natural Kind Terms}

In order to further our understanding of the theory I am both defending and attributing to Gallie, we must now attend in more detail to the nature of the exemplars involved in essentially contested terms or concepts and the nature of the contested relation to them. I will approach this through a comparison with the semantic externalist theory of natural kind terms (such as "water" and "tiger") that was developed in the 196os and 7os by Hilary Putnam and Saul Kripke. ${ }^{11}$ My claim will be that natural kind terms and essentially contested terms are both species of a single semantic genus. As such, they share many interesting properties. According to semantic externalism about natural kind terms, such terms are typically introduced in connection with some concrete thing or things (samples of water, tigers) and through those things come to denote the kinds to which those things belong. In other words, the reference of natural kind terms is not determined by some descriptive content associated with them, something knowledge of which might count as knowing the meaning of the term. Rather, for something to be properly described now as "water," it must be of the same natural kind as paradigmatic samples of that substance in connection with which the term was originally introduced. Current uses of the term continue to be connected to the original sample (and therefore to refer to something of the nature, whatever it is, exhibited by the original

11 Loci classici include Putnam, "The Meaning of "Meaning'" and Kripke, Naming and Necessity. 
sample) through the (causal) historical connections between the sample's baptism and current usage. The resemblance between this account and the account I gave in the previous section of essentially contested terms should be clear. Both essentially contested terms and natural kind terms are, on the respective theories, correctly applied to something now if and only if it bears a certain kind of relation to samples or exemplars that have played an historical role in the use of the term. This is what qualifies them as belonging to a single semantic genus.

The subsumption of essentially contested terms under the same genus as natural kind terms is as important for what it implies about how essentially contested terms do not work as it is for what it implies about how they do work. Externalist theories of natural kind terms were introduced to replace descriptivist theories that saw such terms as being associated with some descriptive content and applying to anything that fitted that description. My suggestion that essentially contested terms function in a similar way to natural kind terms likewise rejects the idea that their meanings are given by some descriptive content that might be offered as a definition. If they were treated descriptively, then the disagreements that caught Gallie's attention would inevitably turn out to be either mere confusions, to be settled by stipulation and disambiguation, or empirical differences about which description people have in fact associated with a term. In neither case would they have the features that impressed Gallie in contests involving them.

Nonetheless, there are significant differences between natural kind terms and essentially contested terms over the nature of both the exemplars or samples and the required relation to them. In the case of natural kind terms, the exemplars are, obviously, natural; in the cases Gallie is interested in, they are cultural. But there is another, bigger difference lurking behind this one. Natural kind terms are typically names of kinds of natural objects or substances water, tin, tigers, electrons. And the exemplars themselves are either objects of the relevant kind or quantities of the relevant substance. In the case of essentially contested terms, the exemplar is something like a stage of a tradition. The exemplar will therefore consist in anything that might be an element of a tradition: cultural objects (e.g. literary works, codes of law), institutions, ways of doing things, people and their actions and intentions, and people's understandings of all of the above. (I don't intend this list to be exhaustive.) With regard to Christianity, for the sake of simplicity, I mentioned, as components of the exemplar, just the Bible and the person and biography of Jesus Christ. In fact, a lot more should be included: the apostles, early ecclesiastical institutions, interpretive and ritual practices, and so on. Given the internal complexity of an exemplar, moreover, in practice, any element of a tradition 
may itself be picked out and treated synechdochally as an exemplar itself. This is the phenomenon Gallie refers to in his conditions II and III.

What, exactly, a tradition is, is itself a difficult and interesting ontological question. One way to think of a tradition, which I adopt here mostly for the sake convenience (though it does seem an independently plausible view of the ontology of traditions) is as a concrete, spatio-temporally extended individual of the kind embraced by such philosophers as David Lewis and Ted Sider. ${ }^{12}$ In that case, an exemplar, what I have characterized as a stage of a tradition, will be literally a temporal part of a tradition. ${ }^{13}$ Needless to say, the boundaries of the exemplary part, both temporally and spatially, may be vague. In some cases, the vagueness will matter for understanding essentially contested terms since a contest may be generated by different ways of drawing the boundaries. For example, the exemplar for Christianity, on my approach, will be an early temporal part of a spatio-temporal entity, which part indisputably contains the Bible and the person and biography of Jesus Christ, among other things. Does it also include the non-canonical gospels? Some claiming the mantle of Christianity today may base their claim largely on their relation to those books and their claim might be contested by others who think these extra-canonical books do not form part of the exemplar. But although some contests may be generated by vagueness over the extent of the exemplar, it is important to see that Gallie's point is not dependent on such vagueness; it depends on the exemplar's internal complexity. The Christian Right and the Christian Left may agree to include in the exemplar only canonical books of the Bible; but one party prioritizes the stories of the Flood and of Sodom and Gomorrah, the laws of Leviticus, and the nightmares of Revelations, while the other prioritizes the Sermon on the Mount and the meekness of the crucified Christ.

Essentially contested terms and natural kind terms both, then, apply to something now just in case it has a certain relation to an original sample or historical exemplar. But what, exactly, is the relation something must have to the original sample or exemplar if a given term is to apply to it correctly?

12 David Lewis, "Survival and Identity", Philosophical Papers, vol. I (New York: Oxford University Press, 1983) and Theodore Sider, Four-Dimensionalism: An Ontology of Persistence and Time (Oxford: Clarendon Press, 2001).

13 See, for exposition of the idea of temporal parts and its associated ontology, the works by Lewis and Sider cited in the previous note. For reasons that should become apparent, my remarks here do not require one to view traditions in this way. Nor, if one does view them this way, does anything I say require that one take the correct theory of parthood for them to be the classical extensional mereology favored by Lewis. See Peter Simons Parts: A Study in Ontology (Oxford: Oxford University Press, 1987) for an account of mereology, both the classical extensional and other varieties. 
In the case of natural kind terms, something is correctly referred to by a use of a term just in case it belongs to the same kind as the exemplar. So the operative relation is belonging to the same kind as. One might wonder why there are not "contests" over natural kind terms in the same way as there are over essentially contested terms. After all, any set of exemplars will presumably belong to many different kinds. (This corresponds to the internal complexity of the exemplar in the case of essentially contested terms.) We may suppose that the exemplars of water, besides belonging to the kind $\mathrm{H}_{2} \mathrm{O}$, all belonged to the kind clear, thirst-quenching liquid. Under certain circumstances the two kinds may fail to coincide. For example, Putnam's thought experiment of Twin Earth is of a place indistinguishable from Earth (by, say, pre-modern standards) but where instead of $\mathrm{H}_{2} \mathrm{O}$, the lakes and rivers are filled with some other clear, thirst-quenching liquid, XYZ. Twin water would therefore share with the exemplars associated with the term "water" membership in the kind clear, thirstquenching liquid but not membership in the kind $\mathrm{H}_{2} \mathrm{O}$. Conversely, quantities of steam or ice would share with those exemplars membership in the kind $\mathrm{H}_{2} \mathrm{O}$ but not in the kind clear, thirst-quenching liquid. Could we here have a contest over the term "water" in which one party took the term to apply to Twin Water but not steam and ice, while another party took the term to apply to steam and ice but not Twin Water? Yes and no. Yes, in that there is some contest here that is, in a sense, structurally similar to the contests in the case of essentially contested terms. The structural similarity is that in both cases, the root of the contest lies in the transition from the concrete (an exemplar or set of samples) to the general (a kind). The concrete is rich; any concrete phenomenon has many, probably infinitely many, features to it. To determine a kind on its basis is effectively to pick out some finite number of these features and ignore the rest. But if the original concretum has infinitely many features, there will be infinitely many different kinds that can be resolved out of it. Semantic externalists generally avoid the appearance of a problem here by building in to their description of the semantic phenomenon with which they are concerned such a method of resolution. Putnam, for example, speaks of the necessity of something's bearing the same liquid as relation to some designated exemplars to be water and more or less takes for granted that for something to be the same liquid as something, it is necessary and sufficient that it share the latter's chemical composition. ${ }^{14}$ (This means that, according to Putnam, "water" does not correctly apply to Twin Water.) Something like deep structure, then, is tacitly assumed to underlie the operative relation. Science has played along, determining that there are indeed deep structures that determine what

14 Putnam, “The Meaning of 'Meaning'”, 225 and passim. 
we call natural kinds. But there is no reason why there could not be a semantic phenomenon in which we introduce a term with reference to a set of samples and the principle only that the term refer to things that are of the same kind (however that is determined) as the members of that set. In that case, people might argue over whether Twin Water or ice are, or are not, of the same kind as the liquid, $\mathrm{H}_{2} \mathrm{O}$ samples. However, the scientific case is not quite like that of essentially contested terms because it is not clear that the contests just envisaged should not be diagnosed as in some sense confused, calling simply for a stipulative answer. ${ }^{15}$ Parties to such a dispute over a word introduced in connection with some liquid $\mathrm{H}_{2} \mathrm{O}$ samples and with the principle that it apply to things of the same kind as the samples (where this is not understood, as it is implicitly by Putnam, to mean of the same deep-structure chemical kind) can simply agree that the term is ambiguous and resolve their differences by disambiguating.

Turning to essentially contested terms, I have put the relation involved in terms of being the heir of. The exemplar is a stage (perhaps a temporal part) of a tradition; a given term now serves to pick out something that has the relation of being the heir of that tradition-stage. Although we will see in due course that this is not sufficient to capture the notion of heirship, a component of that relation is the relation being part of the same tradition as. A necessary condition of one part of a tradition's being the heir of another is that both are parts of a single tradition. I have already said that, for convenience, I will take a tradition to be a temporally extended concrete individual. Suppose, also for the sake of convenience, we think of a natural kind, like water or the species tiger, as a concrete individual of which individual tigers or samples of water are, literally, parts. ${ }^{16}$ Then, in both the cases of essentially contested terms and

15 Two-dimensionalist semantics might perhaps be seen as an attempt to reconcile two such contesting parties. One thinks that Twin Water is of the same kind as the $\mathrm{H}_{2} \mathrm{O}$ samples, and appeals to certain semantic intuitions (involving claims of necessity, etc.) to support the case. The other thinks Twin Water is not of the same kind, and appeals to a different range of semantic intuitions (involving claims of a priority, etc.). The two-dimensionalist argues that the term satisfies both these sets of intuitions in virtue of different semantic features it has. For a brief overview of two-dimensionalism, see my "Modal Epistemology: Our Knowledge of Necessity and Possibility", Philosophy Compass, 3 (2008), 664-684. doi: 10.1111/j.1747-9991.2008.00147.x

16 This is, in my opinion, a very implausible view (even if one detaches it from classical extensional mereology as the theory of parthood) for a variety of reasons, and I mention it here only to help make a point that is independent of it. It is not, however, a view that no-one has advocated. See David Hull “Are Species Really Individuals?", Systematic 
natural kind terms, it is necessary for something to be correctly described by such a term that it bear to the exemplar what David Lewis calls the I-relation, the relation one thing has to another when both are parts of some single thing. ${ }^{17}$ For something now to be correctly described as Christianity, there must be an individual tradition of which the exemplary stage and the currently described phenomenon are both, literally, parts. And for something now to be a tiger, there must be an individual species of which the object now described and sample tigers are all, literally, parts. On our assumptions about the ontologies of natural kinds and traditions, then, we can see that natural kind terms and essentially contested terms all work by means of exemplars and an I-relation. This characterizes the semantic genus of which both kinds of terms are varieties. The reference to an exemplar, and the subsumption of things under a given term through their having the I-relation to that exemplar, makes all the terms in this semantic genus historical, genetic, or externalist. ${ }^{18}$

All of this has been predicated on some assumptions about the ontologies of natural kinds and traditions. If one wishes to drop these assumptions, the point of the preceding paragraph would have to be expressed in terms of a broader kind of relation of which the I-relation proper would be one variety. This broader relation would hold not just when two things were parts of a single whole of a given kind, but when, for example, they were co-instances of a single property, co-members of a single species, etc. Exactly which variety of this broader kind of relation one needed to explain a given historical or genetic term would depend on one's views about the ontology of the kinds of covering entities (traditions, species, substances) involved. I shall not pursue the details of this further.

The similarity between natural kind terms and essentially contested terms, however, goes only so far and we need now to see why. When David Lewis introduced the expression "I-relation," it was in the context of a discussion of

Zoology, 25 (1976), 174-191 for species and W. V. Quine Word and Object (Cambridge: MIT Press, 1960) for substances.

17 Lewis, "Survival and Identity". Since Lewis accepts classical mereology, it follows that any two things are I-related since any two things have a fusion of which they are parts. We had, therefore, better think of a family of I-relations, each tied to some covering concept. Thus there is a relation of being co-parts of an F, another of being co-parts of a G, and so on. The relevant covering concept will be clear from the context here.

18 We can also see that, at least in principle, there might be genetic or historical terms that rely on other kinds of relation to an exemplar. Indeed, if the relation were irreflexive, the exemplar itself would not even be correctly described by the term. 
personal identity. He was responding to a thought experiment in which a person in some way undergoes fission. Suppose a person, A, undergoes such fission, the results of which are two persons $B$ and C. It seems that each of B and $\mathrm{C}$ might have an equal, and good, claim to being the same person as A. Each, we may suppose, has memories of A's life, has A's personality, etc. Yet they cannot both be identical to A since that would imply they were identical to each other. Lewis resolves the problem by arguing that rather than seeing "A," $\mathrm{B}$," and "C" as names of persons, we take them as names of temporal parts of persons, which in turn are seen as temporally extended entities. Since a single thing can be part of two non-identical wholes, his diagnosis is that there is one person that has $\mathrm{A}$ and $\mathrm{B}$ as parts (A and $\mathrm{B}$ are I-related) and another person that has $\mathrm{A}$ and $\mathrm{C}$ as parts (A and $\mathrm{C}$ are I-related), but none that has $\mathrm{B}$ and $\mathrm{C}$ as parts (B and $\mathrm{C}$ are not I-related). Thus $\mathrm{A}$ is actually, simultaneously, a temporal part of two different persons. These two persons overlap at A as two roads or rivers may overlap for a stretch and yet still be distinct.

On Lewis's account, there is, and can be, no contest between B and C over which is part of the same person as the person of which A is a part. The reason, as we have seen, is that such a contest presupposes, incorrectly (and, of course, assuming the possibility of the kind of fission in Lewis's example), that A can be part of only one person. Analogously, if the Christian Right and the Christian Left were to argue over which was a part of the same tradition as that of which the exemplary stage of Christianity is a part, we should give the same answer. Such contest would be illusory. There is one tradition of which the original exemplar and today's Christian Right are parts, and a different one of which the original exemplar and today's Christian Left are parts. These two traditions overlap at the original exemplar (and no doubt at many other places too), which is itself a part of more than one tradition. But this solution is a metaphysical solution to a metaphysical problem. It leaves completely unresolved a different variety of contest. In the episode "Second Chances" of Star Trek: The Next Generation, Commander Riker suffers essentially the fate of fission envisaged in Lewis's thought experiment (owing to a transporter malfunction). One question that might be asked, the one addressed by Lewis, is which of the two resulting Riker-stages is part of the same person as the pre-accident Riker-stage. (The answer, of course, is that there is no single person of which the pre-accident stage is a part and that both of the post-accident stages are co-parts of $a$ person with the pre-accident stage.) But there is another question the two Rikers grapple with, of more practical import: which of them gets to keep the original Riker's trombone. And this, of course, is a synecdoche for the problem of which of the two resulting people gets to continue the life of the original, to work at his job, to access his bank account, etc. Which of them 
inherits the life of the original? ${ }^{19}$ That contest, of course, is not touched by Lewis's dissolution of the metaphysical problem which says that there were two Rikers all along who shared their early years. Here, then, is a contest over inheritance.

On the one hand, then, there is the I-relation, the relation of being a co-part of something (person or tradition) with the original exemplar (early temporal part of the person or tradition) which, as Lewis shows, does not really generate a contest since the original itself might be part of more than one person or tradition. On the other hand, there is a practical contest over who gets to inherit from the original: which of the two Rikers keeps the trombone, which of the two parties keeps the relics, the name, control of the institutional structures, which view is sanctioned by the weight of history, etc. But contests over inheritance turn on heirship. One inherits in virtue of being the rightful heir. And this, I suggest, is the contest involved in essentially contested concepts. Such contests are over who has the right to inherit, over which party is the rightful heir of the exemplar. ${ }^{20}$ Contests over heirship, of course, are lacking in the case of natural kinds, since these are not, or are only incidentally, comprised of things that themselves care about their relation to an exemplar. That is why contests over whether the word "water," introduced in relation to thirstquenching liquid $\mathrm{H}_{2} \mathrm{O}$ samples, is rightfully extended to ice and steam (nonliquid $\mathrm{H}_{2} \mathrm{O}$ ) or to Twin Water (non- $\mathrm{H}_{2} \mathrm{O}$ thirst-quenching liquid) can be settled by stipulation and disambiguation if necessary.

Imagine two children arguing over who rightfully inherits their parents' cow. The younger may point to the fact that the parent loved her best; the older may dispute that, or concede it but point to the practice of primogeniture among neighbors, and so on. In many cases, such disputes are played out against the background of a legal system that either provides the answer as to who is the

19 Having written this, I chanced to review the episode for the first time in many years. It turns out that I have slightly mischaracterized the nature of the drama that unfolds. Nor do they argue over who gets to keep the trombone. It is undisputed by all that it 'belongs' to the one currently in possession of it, who, magnanimously, makes a 'gift' of it to the other. I leave my text unedited, however, since it merely makes explicit what is implicit in my use of scare quotes around "belong" and "gift."

20 This accounts for the fact, prominent in Gallie's discussions of examples, that the relevant contests are not typically over which party, say, is Christianity as such, but over which party is real (or in other contexts, the destined, or the true) Christianity. A competing party may be a kind of Christianity, but it is not the heir. Just so, the contest between the two Rikers is not over which is Riker. They both are. The question is: which is the real Riker. It is very helpful, in thinking through Gallie's examples, to keep this kind of language of being the real, or the true, or the destined such-and-such in mind. 
rightful heir or empowers someone to make one of the parties the rightful heir by judging in her favor. But where disputes concern religious or political traditions, or artistic movements, there is no established, institutionalized method to determine which party is right. Thus disputes cannot be decisively settled except, under some circumstances, by suppression of the weaker party by the stronger. Outside of something that functions like a legal system, there simply is no determinate answer to which, of two conflicting parties, is the rightful heir of the earlier tradition part. This accounts for some of the characteristic features of the kinds of contest that Gallie identified. They cannot be settled by reason because there simply is no objective answer as to which party is right. But reason may play a role in such disputes since it may speak to many issues that shape the contest. It may, for example, be able to show that a feature of the exemplary tradition stage on the basis of which one of the disputants now claims to be the rightful heir of that earlier stage was, in fact, seen at the time as a minor element in the tradition.

One feature of the kinds of dispute in question which I have briefly alluded to above is very significant. Such arguments may well take the form of disputes that appear definitional. That is, the disputants take themselves to be arguing over the meaning of an expression such as "Christianity" or "Conservatism." This is because one is naturally inclined to make points of resemblance to the exemplar appear to win the contest of heirship analytically. If Christianity were defined in terms of love, then the party that now emphasizes its resemblance to those aspects of the exemplar that stress the role of love would seem to win the contest. Hence, their opponents in the contest over heirship would dispute the definition of Christianity in terms of love. Thus arises the notable phenomenon of real disputes that mistakenly take the form of fruitless arguments over definition. And this, in turn, encourages the mistaken belief that Christianity is a concept, something that might be realized under a variety of historical circumstances (or on Twin Earth), rather than a concrete historical reality. ${ }^{21}$

21 I say here that something like Christianity is to be identified with a concrete historical entity, a tradition, rather than with a concept capable of realization under indefinitely many circumstances. But this does not imply that Christianity may not have arisen or existed under other circumstances than those under which it actually did arise and does exist. By way of analogy, consider my chair. This is clearly a concrete entity. But perhaps $i t$, that very chair, might have been built earlier or later than it was, or in a different place, or by a different maker, or from different wood, or from leather and plastic rather than wood. Which of these do and which do not represent real possibilities for it, that chair, will depend on the details of one's views about the identity of chairs (or artifacts in general). So too, it will depend on the details of one's views about the identity of traditions whether 
I have said that essentially contested terms are not, after all, terms for things that are essentially contested. But while such contests may not be essential, they are surely endemic to the kinds of entities in question because while fissions of persons are (at least for the moment) merely science fiction, an analogous process is an almost inevitable fact confronting any human tradition. Even where secession or heresy never actually occur, their threat is a constant possibility for any tradition. ${ }^{22}$ And in fact, one would be hard put to find cases of historically significant traditions where such contest never reared its head. Sometimes, if the existing patrimony is not already large, there may be a split without much contest, since there is not much to contest over; and sometimes, a potential contest may be easily stifled because of an imbalance of force. But the potential for contest is endemic to, and a very deep fact about the nature of, human traditions.

I would like now to consider two prominent objections that have been raised against Gallie's theory of essentially contested concepts. Doing so will allow me, simultaneously, to vindicate Gallie and my interpretation of him, and to deepen our understanding of the phenomenon under discussion. Ernest Gellner objects to Gallie's inclusion of condition VI - which condition, of course, is exactly what I take to be central to what Gallie is doing - in his account of what an essentially contested concept is on the grounds that it is "an application of the 'genetic fallacy' argument: the present functioning of a concept (as of an institution) is logically independent of its history." Even though in some cases, such as Christianity, there is a belief in an exemplar, Gellner argues, "would the relationship of Christian churches and sects turn out to have been quite different, should historical research disprove the historicity of Christ?" The inclusion of VI, "intolerably, makes the status of being 'essentially contested' into a hostage of the past". ${ }^{23}$ A first point to note is Gellner's misconception over the nature of the exemplar involved. Gallie

that very tradition, Christianity, might have arisen earlier or later, on Twin Earth, and so on. Nothing I say here bears, or is intended to bear, on that question.

I thus disagree with those authors, such as Gellner, Selected Philosophical Themes, Volume II: Contemporary Thought and Politics, 107-8 Gray, "On the Contestability of Social and Political Concepts", 336-7 who claim that essentially contested concepts are somehow distinctive of Western liberal modernity. 
clearly does not think that in a case like Christianity, the relevant exemplar is a single person. ${ }^{24}$ It is, as I have argued, rather a stage of a tradition that will include a wide variety of people, events, institutions, texts, and so on. Nor, I think, must the originality of the exemplar be absolute. It is not required, for a contest of the kind Gallie is interested in, that the exemplar that makes the contest genuine rather than illusory or confused be at the beginning of the tradition rightful ownership of which is being contested. When bifurcation in a tradition threatens, the actual distant past may figure into the struggle mostly insofar as the tradition itself has interpreted its past throughout its duration. So the existence of stories about Jesus Christ might, especially some years after the events related in those stories, play exactly the role that a real person might have played. Insofar as the actual history of the tradition has become lost to it, and so does not figure in the tradition's own understanding of itself, it is irrelevant to understanding the kinds of contest that Gallie is concerned with. The effect of a rediscovery of an important historical aspect that has played no role in the development of the tradition may come to figure in current contests over it, but that is far from being necessarily the case. (The discovery of a lost gospel detailing an affair between Jesus and Mary Magdalene, for example, would certainly enter into struggles over the ownership of Christianity, with its difficulties over sexuality, today.)

Nevertheless, Gellner is correct that a concept's or term's status as essentially contested is a hostage to the past, albeit not necessarily the distant past. That is because an essentially contested term is distinguished from a confusedly contested one precisely by the existence of something that is being contested over, and what is being contested over, on my interpretation, is an actual piece of history. People have criticized Putnam's approach to natural kind terms because it allegedly makes the meanings of such terms hostage to the world and its nature beyond the confines of the knowledge and speech patterns of the people using the terms. "Cut the pie anyway you like," says Putnam, “meanings' just ain't in the head". ${ }^{25}$ Nor, we may add, are they necessarily in

24 In similar spirit, Ingram, "Open Concepts and Contested Concepts', 42, dismisses condition VI very quickly because, he says, for a concept like work of art, "it would surely be impossible to postulate an original exemplar". It would, of course, be absurd to postulate the original work of art. But Gallie requires no such thing, as his discussion of the very case of art makes clear. (Incidentally, part of Ingram's confusion is generated by taking "work of art" as the primary formulation of the contested concept or term; what is really the primary formulation is "art." A work of art is a work produced as part of a certain tradition.) 
the present. People may use essentially contested terms without any, or much, knowledge of the histories of the traditions involved just as someone may correctly use the term "water" without knowing anything about its chemical nature. In the case of essentially contested terms, people may even engage in the contests that are waged, incorrectly thinking that they are arguments over definition rather than contests to appropriate history. But none of this means that understanding the ways such terms work does not require adverting to history or the world beyond the ken of a term's current users. In any case, to reject genetic accounts of natural kind and essentially contested terms simply because they commit the so-called genetic fallacy is simply to refuse to engage with the theories being advanced.

The second objection raised against Gallie's theory that I would like to discuss is this. Some commentators have supposed that the expression "essentially contested concept" means a concept such that there is a contest about $i t .{ }^{26}$ But a concept is often, reasonably enough, taken as something individuated by its (conceptual) content. Adopting both these assumptions has two negative consequences. First, it encourages the assimilation of Gallie's theory of essentially contested concepts to other theoretical positions, such as Rawls's distinction between concepts and conceptions, to which it bears a superficial but misleading resemblance. (It is supposed that the concept is accepted by the parties to a contest, and their contest takes the form of their having different conceptions associated with that concept. $)^{27}$ But secondly, and more pointedly, the two assumptions appear to generate a kind of dilemma faced by one who posits the existence of essentially contested concepts. On the one hand, if the concept that is contested is identified by its content, then the existence of genuine disagreement over something, rather than mere miscommunication, implies the existence of some core agreement about conceptual content. Whatever is contested is therefore in some sense peripheral, and not essential to the concept itself. On the other hand, if there is no agreement over the concept itself, then the contest cannot be real since there is no single thing being fought over.

This dilemma is resolved, independently but harmoniously, by two aspects of my interpretation. First, taking Gallie's theory as a semantic theory, a theory about the meanings of certain kinds of words, rather than as a theory about

26 The supposition is explicit in Gray, "On the Contestability of Social and Political Concepts," 344, and Swanton, “On the 'Essential Contestedness' of Political Concepts”, 811 and passim, but is implicit in, I think, all discussions of the subject I have encountered. Swanton (816ff.) has a good discussion of this whole line of objection. 
certain kinds of concepts, removes the temptation to suppose there must be some conceptual content over which the contesting parties agree in order for there to be something they are disagreeing about. But perhaps a deeper response to the dilemma is this. Essentially contested concepts (even supposing we do not switch to talk of terms) are not concepts about which there is a contest; rather they are concepts of contested things. ${ }^{28}$ What makes the contest real rather than illusory is not that both parties agree over some conceptual content; it is that they are arguing over a common exemplar, a stage of a tradition on my view, and the relations of other things to that exemplar. ${ }^{29}$ The contest is over history and its inheritance and not over concepts. It can sometimes appear as if the contest is over something conceptual, or definitional, because there is a tendency to mistake historical concrete realities, like Christianity, for ideas and so a disagreement about what now is real Christianity can look as if it is a disagreement about the real definition of the idea of Christianity. But this is, as I say, a misprision of the real disagreement. ${ }^{30}$

\section{The Range of Essentially Contested Concepts}

In this final section, I address the extension of the concept of an essentially contested concept or term. I have interpreted the concept in such a way as to apply to terms that refer to historical entities. This way of putting things works well for some of Gallie's examples but not for others. And it does not

28 And in fact, Gallie is careful to talk about contests over the proper use, application, or function of concepts, not over their meanings or definitions.

29 Swanton, in her treatment of the dilemma, correctly sees that it is the exemplar that provides the way out, but she makes two mistakes in her presentation of this solution. First, she thinks that taking the exemplar as the unifying factor in a contest does violence to the idea of essentially contested concepts. On the contrary, I believe it does justice to Gallie, and violence only to a tradition of misinterpretation of his view. Secondly, she takes the exemplar to be endoxa, things agreed on by the wise or the many and expressed in terms of the essentially contested concept at issue. Since a tradition, of course, is partly constituted by the things people in and out of the tradition say, she is close but not quite on target with this suggestion.

30 Gellner charges that Gallie's commitment to the importance of the exemplar "betray[s] his own idea: he talks as if, behind each 'essentially contested concept', there was, hidden away in some Platonic heaven, a non-contested, unambiguously defined and fully determinate concept or exemplar" (97, my emphasis). The disjunction "concept or exemplar" is, it should now be evident, a conflation that ends up standing Gallie's actual view entirely on its head. 
seem to include a large range of cases that have generally been assumed to be examples of essentially contested concepts. Some comment is needed about what is going on here.

First, then, Gallie's own examples. ${ }^{31}$ The two most fully worked out cases he discusses are Christianity and art. I have already spoken extensively about Christianity. Regarding art, I think Gallie is right that disputes about what is art are disputes about the continuation and centre of gravity of an historical tradition and his views on this should be seen in the light of the work of aestheticians like Arthur Danto (1964) and Jerrold Levinson (1979), the latter of whom, especially, develops a theory of the nature of art that makes perfect sense of Gallie's position on it. ${ }^{32}$ Gallie also discusses two further 'live' examples: social justice and democracy. Social justice, he argues, is not a good example of an essentially contested concept. This judgment is significant when we remember that it is precisely the concept of social justice, and others like it, that are so often uncritically taken as examples of essentially contested concepts. Regarding democracy, as a political idea, it would not be an example of an historical entity and hence the term "democracy" would not function in the way I have suggested terms in his target class do. But Gallie's inconsistent use of capitalization (he mostly writes "Democracy") suggests that he is also thinking of an historical movement or tradition, something analogous to Liberalism or Conservatism, reference to which would function in the way I have tried to capture in terms of an exemplar and an I-relation.

Without discussing them, Gallie also mentions a host of other possible examples of his target class. I cannot deal with them all, but two general observations are in order. Some of these other cases are of things that are in some sense dependent on more general things that are clear instances of the target class, such as coloration and dogma, dependent on art and Christianity respectively. Such things may or may not be historical entities in their own right, but even if they are not, we can expect the terms to function in a way that is dependent on the historical nature of the entity with which they are connected and hence for them to exhibit signs of the kinds of contest Gallie is concerned with. Conversely, some of the examples are at a higher level of generality than his paradigm cases, for example, religion and law. Here, I think, Gallie is wrong to see them as examples of the phenomenon he is really

31 I will not discuss his example concerning championship in an invented game since it would require too much space to make sense of.

32 Arthur Danto, "The Artworld", Journal of Philosophy, 61 (1960), 571-84 and Jerrold Levinson, "Defining Art Historically", British Journal of Aesthetics, 19 (1979), 232-50. 
interested in. ${ }^{33}$ Religions or bodies of law are historical entities but the kinds they form, religion and law, need not be, and need not be subject to the kinds of contests Gallie identifies. Arguments over whether, say, Buddhism or Marxism are religions are more like the kinds of arguments to be settled by stipulation than arguments over who is the heir to the tradition of Christ and the Bible.

Those who have ostensibly been most responsive to Gallie's work have taken the field of essentially contested concepts to be occupied principally by such things as social justice, freedom, power, and so on. In most of these cases, I believe that the authors are simply wrong to think of these as examples of Gallie's phenomenon, and it is striking, as I have noted above, that such treatments usually involve a more or less explicit rejection of Gallie's view about the importance of an exemplar in understanding essentially contested concepts. The authors concerned with these concepts may be right to take them as examples of concepts that are not to be understood simply by supplying necessary and sufficient conditions. But there is no reason to think that there is only one kind of concept that cannot be understood this way and hence that if Gallie is talking about concepts that cannot be understood in terms of necessary and sufficient conditions, then all concepts that cannot be so understood must be of the kind Gallie was interested in. The very interesting ways in which concepts like freedom or power function, and the kinds of disputes to which they give rise, certainly deserve to be studied. It may even be that they behave in a way that would make the phrase "essentially contested concepts" an apt name for them. But Gallie tells us (more or less) what he means by that expression, and there is nothing to be gained by ignoring the differences between those other concepts and what Gallie is actually focused on. ${ }^{34}$

33 An indication that Gallie may be confused here is provided by the fact that he says he is going to discuss the case of religion, but immediately switches to discussing Christianity instead.

Many thanks, for helpful discussion of earlier drafts of this paper, to Brad Cokelet, Giovanna Pompele, Michael Slote, Clark Wolf, a referee for this journal, and audiences at the Florida Philosophical Association and at the graduate research seminar in the philosophy department at the University of Haifa. 